\section{TRIHEXYPHENIDYL (BENZHEXOL) IN CLOZAPINE-INDUCED NOCTURNAL ENURESIS AND SIALORRHEA}

Sir,

Clozapine is an atypical antipsychotic medication. It is the agent of choice to treat patients with schizophrenia who are treatment-resistant and who are prone to extrapyramidal symptoms. However, besides occasional serious and life-threatening side effects like agranulocytosis, myocarditis, and seizures, clozapine is often discontinued because of many common and troublesome side effects like sialorrhea, sedation, weight gain, and nocturnal enuresis in up to $17 \%$ of patients. ${ }^{[1]}$ Clozapine-induced sialorrhea occurs at rates varying from 10 to $80 \%$ as reported in the literature. ${ }^{[2]}$ Nocturnal enuresis is a less commonly reported side effect with a reported frequency varying from as little as $0.23 \%$ to as high as $41 \% .^{[3,4]}$

We wish to report here a case of schizophrenia along with harmful use of cannabis, who developed both sialorrhea and enuresis while on clozapine, and who showed improvement in both the symptoms after receiving trihexiphenidyl.

A 21 year-old, unmarried Hindu male was found to be suffering from schizophrenia as per the criteria of ICD-10, along with harmful use of cannabis for the last four years. His past, family and personal history were nonsignificant except for the cannabis use. In view of nonresponse to risperidone (up to 8 $\mathrm{mg}$ per day) and haloperidol (up to $30 \mathrm{mg}$ per day), each for a period of about four months, despite being abstinent from cannabis, the patient was started on clozapine which was gradually titrated to a dose of $350 \mathrm{mg}$ over a period of three weeks. He was also started on clonazepam $2 \mathrm{mg}$ per day in divided doses for marked aggression and sleep problems. At this dose, the patient complained of bed-wetting during the night time everyday, which was distressing for the patient. On occasions, he would report that he would not be able to get up from sleep. Also, he developed troublesome sialorrhea, which occurred during both night and day, but would occur more during the night time. The results of investigations done at this time including EEG, USG of the abdomen, $\mathrm{X}$-ray KUB and urinanalysis were all within normal limits. The time of the dose of clozapine was shifted to morning and afternoon and clonazepam was stopped but there was no improvement in his symptoms. As a result, amitriptyline was started at a dose of $25 \mathrm{mg}$ per day and increased to $50 \mathrm{mg}$ per day. However, the patient reported excessive sedation and would report dizziness. As a result, it was stopped after about one week and the patient was started on trihexiphenidyl $6 \mathrm{mg}$ per day in divided doses, at which there was complete resolution of enuresis after about five days. There was also marked reduction of nocturnal sialorrhea, with disappearance of daytime sialorrhea, as reported by the patient and also observed by the staff objectively. The patient did not report any side effects related to the use of trihexyphenidyl like constipation, dizziness, etc and he tolerated it well. The patient showed good maintenance of response for the next three months of follow-up on this combination.

In our case, clozapine could not be replaced 
as the patient had shown improvement with the drug and had been classified as being treatment-resistant.

Trihexiphenidyl is a centrally acting M1 antagonist and has been used previously in an open label study for the treatment of sialorrhea induced by clozapine at a mean dosage of around 10.7 mg per day. ${ }^{[5]}$ A reduction of $44 \%$ was observed in nocturnal hypersalivation in 14 patients with chronic schizophrenia in this study. It has also been reported in a single case report to be helpful for clozapine-induced enuresis at a dose of 5 mg per day ${ }^{[6]}$ Although the exact pathogenesis for both these side effects is not very clear, the cholinergic system seems to play an important role. Besides the role of the cholinergic system, excessive sedation may also play a role in the pathogenesis of enuresis. However, in our case, the patient did not report any improvement after stopping of clonazepam.

Drugs found to be useful in clozapine-induced sialorrhea include anticholinergic agents, alpha-2 adrenoreceptor antagonists and other agents like amisulpride, sulpride, etc. ${ }^{[2]}$ Drugs such as desmopressin, oxybutynin, and trihexyphenidyl have been helpful in clozapine-induced enuresis. ${ }^{[7]}$

Caution needs to be observed while using a combination of trihexiphenidyl with clozapine as there may be an increase in anticholinergic effects as well as cognitive disturbances. Nevertheless, when enuresis and sialorrhea due to clozapine coexist, trihexiphenidyl may be an important therapeutic option. This may be especially true because it might not be possible to withdraw clozapine in patients who do not respond to other antipsychotics and who develop troublesome side effects. More studies are warranted to establish the role of various drugs for these side effects related to clozapine.

\section{ASHISH AGGARWAL, AMIT GARG',} R. C. JILOHA ${ }^{1}$

Department of Psychiatry, Indira Gandhi Medical College, Shimla, 'Department of Psychiatry, Maulana Azad Medical College and associated G.B. Pant Hospital, New Delhi, India

Correspondence: Dr Ashish Aggarwal, Department of Psychiatry, Indira Gandhi Medical College, Shimla -170 001, Himachal Pradesh, India. E-mail: drashish1980@yahoo.co.in

\section{REFERENCES}

1. Young CR, Bowers MB Jr, Mazure CM. Management of the adverse effects of clozapine. Schizophr Bull 1998;24:381-90.

2. Praharaj SK, Arora M, Gandotra S. Clozapineinduced sialorrhea: Pathophysiology and management strategies. Psychopharmacology 2006; 85:265-73.

3. Aronowitz JS, Safferman AZ, Lieberman JA. Management of clozapine-induced enuresis. Am J Psychiatry 1995;152:472.

4. Lin CC, Bai YM, Chen JY, Lin CY, Lan TH. A retrospective study of clozapine and urinary incontinence in Chinese in-patients. Acta Psychiatr Scand 1999;100:158-61.

5. Spivak B, Adlersberg S, Rosen L, Gonen N, Mester R, Weizmen A. Trihexyphenidyl treatment of clozapine-induced hypersalivation. Int Clin Psychopharmacol 1997;12:213-5.

6. Poyurovski M, Modai I, Weizman A. Trihexyphenidyl as a possible therapeutic option in clozapine induced nocturnal enuresis. Int Clin Psychopharmacol 1996;11:61-3.

7. Kho $\mathrm{KH}$, Nielsen O. Clozapine-induced nocturnal enuresis: Diagnostic and treatment issues. Psychiatr Bull 2001;25:232-3.

DOI: $10.4103 / 0019-5359.57642$

PMID: 19901488 